\title{
Author Spotlight: Andrea Sciannamea
}

\section{Andrea Sciannamea $^{1}$}

Published online: 20 June 2020

(c) Springer Science+Business Media, LLC, part of Springer Nature 2020

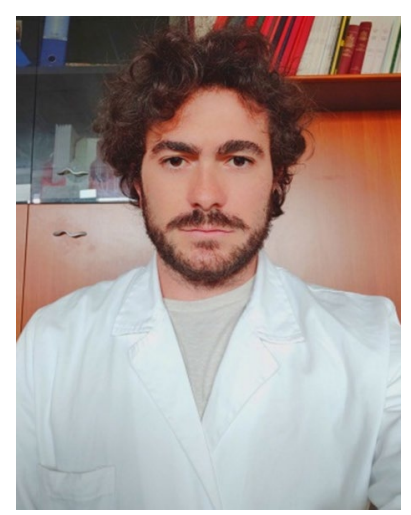

Dr. Andrea Sciannamea is currently a 5 th year surgical resident at St. Orsola University Hospital in Bologna. He will become a general surgeon following his graduation on November 2020. His clinical and research interests include bariatric surgery, IBD surgery, and oncologic surgery.

Publisher's Note Springer Nature remains neutral with regard to jurisdictional claims in published maps and institutional affiliations.

Andrea Sciannamea sciannagol@gmail.com

1 St. Orsola University Hospital, Bologna, Italy 